\title{
COLOMBIA: ¿HACIA UNA REESTRUCTURACIÓN DEL SISTEMA POLÍTICO?
}

Colombia: Towards a restructured political system?

\section{PAOLA MONTILLA}

Universidad Externado de Colombia

\begin{abstract}
RESUMEN
En Colombia se siente un ambiente de cambio, en un momento en que se adelantan negociaciones de paz con las FARC, después de más de medio siglo de conflicto armado. En diversos aspectos, las negociaciones de paz hacen eco en cuestiones aún no resultas en la sociedad como los problemas de desarrollo rural y la falta de participación política de los movimientos de izquierda, que hasta hace dos décadas, fue obstruida por el bipartidismo. En este escenario los acuerdos de La Habana y el posconflicto se han convertido en el epicentro de la política y en la mayor apuesta del Gobierno para ganar los próximos comicios. Este artículo analiza el penúltimo año de la presidencia de Juan Manuel Santos, sus principales decisiones en política nacional e internacional y señala la configuración de fuerzas para las elecciones del 2014.
\end{abstract}

Palabras clave: Juan Manuel Santos, proceso de paz, movilizaciones campesinas, elecciones 2014.

\begin{abstract}
After over half a century of armed conflict, the political atmosphere in Colombia is changing. Peace talks with the FARC (Colombian Revolutionary Armed Forces) have spurred public debate around two unresolved issues: rural development, and the political participation of left-wing parties -hindered by bipartisanism until two decades ago. In this scenario, the Habana agreements and an eventual post-conflict have become the center of the political arena as well as the major asset of the government facing the next election. This paper analyses the next-to-last year of Juan Manuel Santos's presidency, the major decisions in national and international policy, and indicates the configuration of forces for the 2014 elections.
\end{abstract}

Key words: Juan Manuel Santos, Peace process, farmer mobilisation, 2014 elections. 


\section{INTRODUCCIÓN}

Luego de más de un año de negociaciones entre el gobierno y las Fuerzas Armadas Revolucionarias de Colombia -Ejército del Pueblo (FARC-EP)- se han suscrito algunos acuerdos parciales sobre dos problemáticas que han atravesado la sociedad colombiana. Entre estos temas se destacan la cuestión de la tenencia y redistribución de la tierra que remite a un conflicto más general de desarrollo rural y que desde los años cincuenta ha formado parte del ideal programático del grupo guerrillero. El segundo aspecto tramita cuestiones relacionadas con la participación política de la izquierda en un sistema político dominado, durante largas décadas, por el bipartidismo. La exclusión de estos sectores y, en general, de terceras fuerzas que no encajaban dentro del Partido Liberal o el Conservador, generó diversos fenómenos de inestabilidad política en la historia del país como lo revela, en particular, el surgimiento de las FARC, que pretenden, en sus ideales revolucionarios, transformar la configuración política.

La discusión de estos dos primeros puntos de la Agenda de Negociación auguran que: de firmarse la paz el país transitaría hacia una reforma estructural de sus instituciones. En este escenario los acuerdos de paz y el posconflicto se han convertido en el epicentro del debate político y en la mayor apuesta del gobierno para ganar las elecciones del 2014.

Durante el último año el presidente Santos tuvo que hacer frente a varias olas de protestas sociales que repercutieron sobre su popularidad y desencadenaron un cambio en el gabinete. Las movilizaciones campesinas en el Catatumbo y el paro agrario unificaron demandas históricas y peticiones coyunturales, que exigieron por parte del gobierno respuestas inmediatas y no planificadas.

En lo económico, el país obtuvo un balance positivo. La inflación registró el nivel más bajo desde 1955 (1,94\%). El desempleo, por su parte, cerró el año con cifras históricas de un solo dígito $(9,6 \%$ ) y el crecimiento del PIB fue del $4 \%$; aunque no corresponde exactamente a las proyecciones del gobierno en 2012, debe ser valorado en medio de una coyuntura internacional difícil. La inversión extranjera directa, durante el tercer trimestre de 2013, alcanzó US\$13.251 millones, 13\% más que el mismo periodo de 2012. Los sectores que más se destacan son la industria extractiva con el $48,6 \%$ de participación y la industria manufacturera (15,5\%). El aumento de estas cifras ratifica la confianza que los inversionistas le han dado el país en los últimos años. No obstante, estos indicadores macroeconómicos favorables ocultan desigualdades en muchos sectores y regiones, una porción importante de la población vive en condiciones precarias, potencialmente explosivas en el ámbito social.

Basado en una economía dinámica y en el retroceso de las dinámicas del conflicto armado, Colombia ha logrado una mayor inserción en el escenario internacional. Por un lado consiguió posicionarse como uno de los países líderes en la región, su adhesión a la OCDE y la participación en diferentes acuerdos regionales así lo demuestran. Pero, por otra parte, el gobierno aún no clarifica su posición frente el fallo de la Corte Internacional de Justicia (CIJ) en el diferendo limítrofe con Nicaragua. Un tema de crispación a nivel 
internacional, por las connotaciones ideológicas que está tomando la posición de este país centroamericano en la región.

El objetivo de este documento es analizar el penúltimo año de gobierno del presidente Juan Manuel Santos. En este sentido, en la primera parte se reseñan los principales hechos y decisiones en política nacional e internacional, haciendo énfasis en las negociaciones de paz. En la segunda sección se expone cómo se reconfiguró el escenario político con el surgimiento de nuevos partidos y se presenta una aproximación al mapa político para las elecciones legislativas y presidenciales.

\section{UN AÑO DIFÍCIL PARA EL GOBIERNO DEL PRESIDENTE SANTOS}

El programa de gobierno del presidente Juan Manuel Santos "prosperidad democrática" no ha tenido un mensaje claro en los ciudadanos. Algunos errores de comunicación le han impedido consolidar una narrativa que identifique su gestión. En contraste con el programa de "seguridad democrática", que mantuvo la popularidad del expresidente Álvaro Uribe en el 80 por ciento, los ciudadanos no han logrado reconocer la directriz de este gobierno. A diferencia de lo que se afirmaba hace años, el presidente Santos no se inscribe en la línea de acción del uribismo. Una agenda de gobierno que no pone el acento en la seguridad y un estilo de gobernar por consenso (Wills, 2011) han marcado la diferencia con su antecesor.

El Presidente encaminó su agenda de gobierno a las negociaciones de paz, aprobó reformas estructurales como la ley de víctimas y la restitución de tierras, políticas que, sin lugar a dudas, allanan el camino para un posible escenario de posconflicto. Sin embargo, la expectativa inicial de un proceso que no duraría más de un año no se cumplió y los ataques a la población civil, por parte de algunos frentes de la FARC, le han restado credibilidad al Presidente.

Por otro lado, en el último año el gobierno tuvo que responder a una violenta oleada de protestas. En septiembre de 2013 el presidente Santos alcanzó su nivel más bajo de favoritismo (21 por ciento). La percepción que tenían los ciudadanos del Presidente se deterioró tras las protestas sociales que canalizaron las demandas de varios sectores sociales (ver Cuadro 1). La magnitud de los reclamos y el impacto sobre la capacidad de gestión del gobierno derivó en un cambio ministerial. El Presidente nombró a cinco nuevos ministros ${ }^{1}$ en las carteras que, directa o indirectamente, se vieron afectadas por las manifestaciones: Interior, Agricultura, Minas y Energía, y Ambiente y Desarrollo sostenible. $^{2}$

1 El revolcón ministerial incluyó también el Ministerio de Justicia, la directora nacional de Planeación y al secretario general de la Presidencia.

2 Ver: http://www.semana.com/nacion/articulo/santos-designa-el-gabinete-por-la-paz/356600-3 
Cuadro 1. Imagen favorable del presidente Juan Manuel Santos, 2013

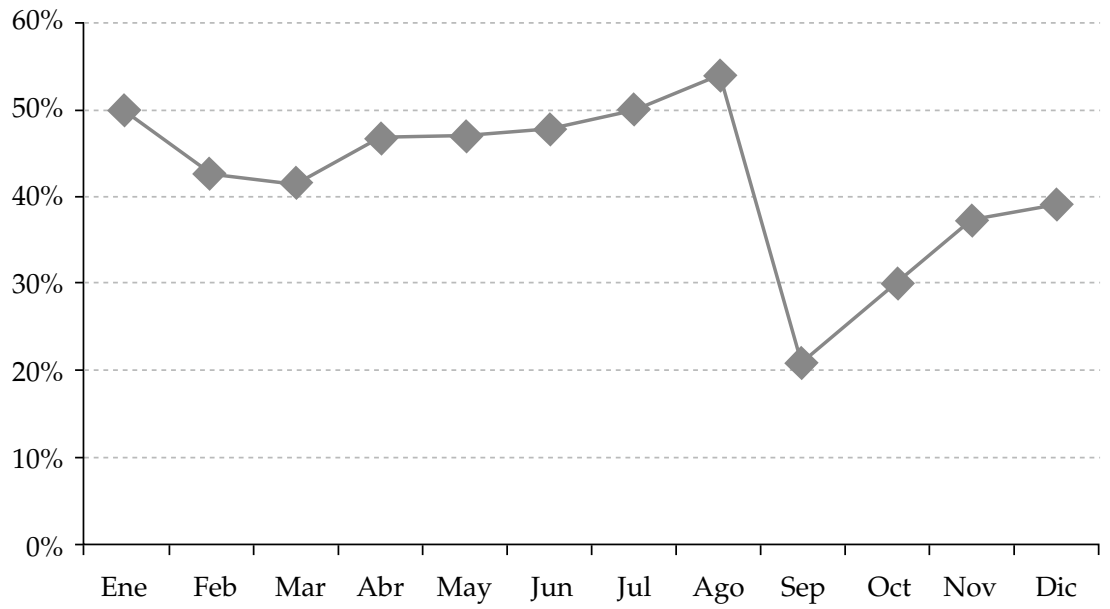

Fuente: Elaboración propia a partir de datos de Gallup (2013).

Esta decisión si bien fue una respuesta inmediata a la crisis de gobernabilidad, también fue una decisión política que buscaba fomentar consenso. En ese sentido, un primer objetivo era garantizar la reelección de sus políticas, por lo que mantuvo dentro de su gabinete representantes de los partidos de la coalición. El segundo propósito fue enmudecer las críticas en contra de la "bogotanización" y la baja representación de las regiones en los ministerios. Una investigación sobre la trayectoria de los funcionarios de alta función pública subrayó que el 73\% de ellos provienen de las cinco principales ciudades del país y, de este porcentaje, el 50\% son bogotanos (Roth, 2013). En este sentido, el nombramiento de los nuevos ministros estuvo mediado por el interés de incorporar políticos regionales. ${ }^{3}$

\section{El paro nacional: Una intercepción de diferentes demandas}

La agitación social que se observó desde mediados del 2013 no es una expresión habitual en la sociedad colombiana. De acuerdo con los datos del observatorio del conflicto social del Ministerio del Trabajo y de la Policía Nacional, en este año se alcanzó un pico histórico de 3.500 protestas en todo el territorio nacional. En contraste, en 2009, se registraron 1.600 incidentes y 1.700 en 2010 (Cuadro 2).

Si bien algunas de estas demandas son peticiones históricas, de sectores como el campesino, la acción social reivindicativa no ha sido una constante. Los estudios sobre la protesta social en Colombia señalan que la centralización política y la ineficacia de los mecanismos de representación han llevado a que los ciudadanos utilicen las vías contestarias para influir en el sistema político. Sin embargo, la dispersión de las demandas, el mal 
Cuadro 2: Protesta social en Colombia 2002 - 2013



Fuente: Observatorio del conflicto social. Ministerio del Trabajo y Policía Nacional (2013).

desempeño económico -el desempleo y los bajos salarios- y la debilidad de la sociedad civil ha menguado la organización de los ciudadanos (Velasco, 2006; Calderón, 2012). Conjuntamente, la violencia ha contribuido a la fractura de los actores contestatarios. Durante los años más álgidos del conflicto se logró imponer una especie de ley del silencio. El asesinato selectivo de dirigentes y miembros de organizaciones sociales debilitó, y en otros casos destruyó, las acciones colectivas (Archila, 2006; Cinep, 2009).

La magnitud del paro nacional convocado en agosto impactó en la agenda del gobierno, y para algunos es un indicador del fortalecimiento de otras formas de negociación con el Estado, que en cierta manera, recrean una nueva expresión de ciudadanía. El paro fue una expresión variopinta que incluyó diversas manifestaciones sociales. Algunas reivindicaciones hacen alusión a reclamos sindicales habituales, como por ejemplo mejores condiciones laborales para los trabajadores de la educación o mayores garantías para los transportadores informales. Pero otras tienen sus raíces en viejas demandas al Estado, como las expresadas por los campesinos.

Los cultivadores de café, desde febrero, se declararon en contra de la caída del precio del grano. Mediante marchas y bloqueos de carreteras los caficultores exigieron la fijación de un precio estable e independiente del mercado internacional. ${ }^{4}$ Las manifestaciones que se extendieron por varias zonas del país implicaron el desabastecimiento de alimentos y enfrentamientos con la fuerza pública. La magnitud de la protesta generó una gran crisis de gobernabilidad que dio vía libre a la movilización de otros productores agrícolas -paperos y cocaleros-, sectores campesinos y estudiantes.

4 Además, en el pliego de peticiones se solicitaban políticas de fomento, un control de precios a los agroinsumos, el congelamiento de los impuestos al gremio y rechazaban la explotación minera en las zonas cafeteras. 


\section{El movimiento campesino}

En la actualidad, el campesinado es un sector amplio y heterogéneo donde interactúan diversos actores, que tienen en común el apego a la tierra. Las diferencias entre los grupos que hacen parte del sector campesino depende de los sistemas de producción, la modalidad de acceso a las tierras y las diferencias geográficas y culturales (Cinep, 2013). Las recientes manifestaciones fueron impulsadas por los campesinos de la zona norte santandereana del Catatumbo, agrupados en la Asociación de Campesinos (Ascamat). Durante 56 días bloquearon las carreteras e incitaron a otros sectores -indígenas- a movilizarse.

Las luchas emprendidas por los campesinos están motivadas por una variedad de demandas que sintetizan la inasistencia del Estado en las zonas rurales, pero también, en los continuos fracasos en la implementación de las políticas públicas que abordaban el conflicto agrario. La concentración de la tierra sigue generando reclamos, luego del fracaso de la reforma agraria. Así como la falta de infraestructura para sacar sus productos al mercado, la prestación de servicios sociales básicos y la participación de las comunidades locales en los planes de inversión.

Sin embargo, estas demandas históricas se conjugaron con peticiones más circunstanciales tras la aparición de la locomotora minera. En el repertorio de las movilizaciones campesinas se insertaron reclamos medioambientales y en contra de la precarización del trabajo rural, provocada por la expansión de la industria extractiva. La ampliación de la frontera de explotación ha afectado negativamente a los pobladores de las zonas aledañas. La contaminación ambiental ha tenido repercusiones en la salud. Y la desregulación laboral junto a la vulnerabilidad de las comunidades -frente al abuso de la fuerza- ha profundizado el desequilibrio social en las zonas de explotación. ${ }^{5}$

Aunque el Presidente trató de minimizar las dimensiones de la protesta, finalmente tuvo que conformar una comisión negociadora. La Mesa Nacional Agropecuaria de Interlocución y Acuerdos (MIA) acordó subsidios de desempleo, asistencia alimentaria y la ejecución de proyectos productivos para el campo.

\section{La protesta estudiantil}

El movimiento estudiantil, que se originó en las primeras décadas del siglo XX, ha sido un actor político intermitente en la sociedad colombiana. Sus primeras manifestaciones se presentaron en los años veinte, paralelas a un proceso de modernización y de emergencia de las clases medias. En las décadas que siguieron las protestas fueron perdiendo intensidad, hasta la década de los setenta. En 1971 se presentó un punto de inflexión, cuando la Universidad del Valle convocó a un paro nacional que fue respaldado por un gran número de universidades públicas y privadas. La protesta exigía mayores procesos

Ver al respecto el Informe de Tierra Digna y el Centro de Estudios Políticos para las Relaciones Internacionales y el Desarrollo - CEPRID en : http://www.nodo50.org/ceprid/spip.php?article83 y http://www.tierradigna. org/ 
de democratización para la elección de las directivas universitarias, el retiro de los fondos de financiación extranjeros y una subvención más adecuada para la universidad pública (Archila, 2012).

En 2011 el presidente Santos presentó un proyecto de reforma educativa que rápidamente activó la protesta estudiantil. El movimiento estudiantil infundido en el ideario de 1971 redactó, de nuevo, un Programa Mínimo para la Educación. Los reclamos estudiantiles atañen, entre otros aspectos, a la autonomía universitaria, la financiación de las entidades públicas, la calidad académica y los derechos humanos. Las agrupaciones estudiantiles se congregaron en la Mesa Amplia Nacional Estudiantil (MANE) que, apoyada por la Federación Colombiana de Educadores (FECODE), logró hundir la propuesta. Desde entonces el gobierno instauró mesas de diálogo para diseñar una política participativa y consensuada, pero aún no existe ningún acuerdo. ${ }^{6}$

Sin embargo, la magnitud que adquirieron las movilizaciones y el impacto en la definición de la agenda de gobierno y en la opinión pública empoderaron al colectivo estudiantil. La naturaleza pacífica de las protestas y la inclusión de repertorios creativos, como el desnudatón y la besatón -besar policías-, ha desestigmatizado la protesta y generado un fuerte apoyo social.

Es así que el movimiento estudiantil, históricamente ${ }^{7}$ alineado a una ideología de izquierda, en el 2013 se desbordó hacia otros temas políticos. Durante el paro nacional, la MANE convocó a una nueva jornada de protesta, en todo el país, bajo la consigna "yo quiero calidad con gratuidad". Los estudiantes reclamaron mayor autonomía para los centros de educación superior, pero también acompañaron las reivindicaciones del agro y de las organizaciones obreras.

En síntesis, la utilización de vías de hecho fue una estrategia generalizada por los actores sociales que obligó al gobierno a ceder en muchas de las peticiones. Para los cultivadores de café y los campesinos se acordaron subsidios y políticas de desarrollo agrícola. Igualmente se formalizaron comisiones de trabajo para abordar el control de precio a los fertilizantes y la erradicación de la minería en las zonas de cultivo. Por su parte, los estudiantes se mantienen en las mesas de diálogo con el Ministerio de Educación, lo que hace prever que el ciclo de protesta estudiantil aún no está cerrado.

La movilización social sin precedentes que vivió el país durante este último año generó dos lecturas. Mientras que para algunos la respuesta que dio el gobierno es una muestra de la falta de coherencia de su programa y abre la puerta a la utilización de las vías de hecho para solucionar los problemas. Para otros, el reconocimiento político de sectores históricamente alejados como los campesinos, y el diseño, aunque parsimonioso, de políticas públicas concertadas está en sincronía con un cambio en la manera de gobernar del presidente Santos. No obstante, la ampliación de los repertorios de protesta en los

6 A mediados del año se anunció que el Consejo Nacional de Educación Superior (CESU) tendría lista la propuesta en diciembre, pero luego la ministra declaró que la "esperaba" para enero de 2014.

7 En la década del setenta en el gobierno de Misael Pastrana (1970-1974) diversos movimientos sociales, entre ellos el estudiantil, presionaron por llevar a cabo una reforma agraria. 
últimos años, y el cese de la estigmatización parecen demostrar que el país está haciendo una experiencia de una sociedad contestataria.

\section{El camino de la paz: Las negociaciones en La Habana}

En el 2012, luego de sucesivos ejercicios de interlocución, treguas humanitarias y procesos de negociación fallidos, las FARC-EP ${ }^{8}$ manifestaron su voluntad de poner fin al conflicto armado. El último acercamiento frustrado se produjo durante la presidencia de Andrés Pastrana (1998-2002). En ese momento ni el gobierno ni las FARC expresaron reformas viables para poner fin al conflicto. Por un lado, el gobierno encaminó sus esfuerzos al desarrollo del Plan Colombia. Y las FARC por su parte mantuvieron las hostilidades militares y las violaciones al DIH (Villaraga, 2013), perdiendo su credibilidad política9 (Pécaut, 2013: 25).

Cuando el presidente Álvaro Uribe (2002-2010) asume el gobierno se plantea una lucha frontal contra las fuerzas subversivas, bajo el nombre de la política de "Seguridad Democrática" y se congela cualquier tipo de acercamiento. La arremetida militar contra la guerrilla, comandada por el Ejército, quebró la simetría militar que caracterizó el conflicto colombiano por mucho tiempo (Zinecker, 2013: 74).

La menguada credibilidad política del grupo guerrillero y la desigualdad militar en la que se encontraban llevaron a las FARC a pactar las condiciones de los diálogos de paz. Desde el inicio el gobierno fue enfático en no repetir los errores de las negociaciones precedentes: no al cese al fuego, no zonas desmilitarizadas, sin un espectáculo mediático (el gobierno al final de cada ronda de negociación emite un comunicado sobre los asuntos pactados) y, lo más importante, una hoja de ruta que define el camino de las negociaciones y los seis puntos a tratar. Aunque los acuerdos estarán condicionados a la firma de un pacto definitivo (Massé, 2013: 32).

Los temas descritos en la Agenda de negociación no se distancian de los pilares programáticos asumidos por las FARC desde los años cincuenta. Una reforma agraria integral y la inclusión política de los grupos de izquierda constituyeron los dos primeros temas a debatir. Los posteriores encuentros deberán desarrollar las cuatro materias pendientes: el problema de las drogas; la desmovilización y la dejación de armas; víctimas, es decir, mecanismos de justicia transicional y, por último, refrendación y garantías.

En los primeros ciclos de diálogo se logró un consenso parcial sobre desarrollo rural y participación política. En mayo de 2013 el gobierno emitió un primer comunicado señalando los acuerdos a los que se había llegado: regularización de los derechos de propiedad y, en consecuencia, la redistribución de tierras al pequeño productor,

8 Tanto el ELN como el gobierno han manifestado su interés, sin embargo a la fecha no se tiene conocimiento de un acuerdo oficial para el establecimiento de una mesa de negociación.

9 Las extensivas prácticas de secuestro a civiles y los ascendentes vínculos de las FARC con el narcotráfico socavaron la reputación de este grupo guerrillero. Además, la opinión pública consideró que la zona de despegue pactada propició una recuperación militar de la guerrilla. 
mediante la creación de un Fondo de Tierras para la Paz; ${ }^{10}$ actualización del catastro rural; medidas para el desarrollo integral del agro (planes de vivienda, agua potable, asistencia técnica, capacitación, educación, adecuación de tierras, infraestructura y líneas especiales de crédito). Sin embargo, no se tomó ninguna resolución sobre las zonas de reserva campesina y la participación del capital extranjero.

Alrededor de la participación política el gobierno y las FARC suscribieron algunos compromisos. El objetivo es brindar a la guerrilla las garantías mínimas para facilitar su tránsito a la vida política, así como robustecer la democracia por la vía de la participación ciudadana.

El acuerdo establece la creación de una Comisión -conformada por partidos políticos, movimientos sociales y académicos- para definir los lineamientos de un estatuto para la oposición. Así como la instauración de un sistema integral de seguridad para la protección de todos los miembros de organizaciones y movimientos sociales que se declaren en oposición al gobierno.

Por otra parte se propone una revisión integral del régimen electoral, para que los movimientos políticos que no consigan el umbral conserven la personería jurídica. En esta vía, y con el fin de incluir a los nuevos partidos en la competencia política, se pretende aumentar los fondos de financiación y promover campañas de divulgación para las nuevas organizaciones -fortalecer los medios de comunicación comunitarios y un canal institucional de televisión cerrada-.

La reforma más importante es la creación de Circunscripciones Transitorias Especiales de Paz para los territorios más afectados por el conflicto. En estas zonas se elegirá un número, aún no definido, de representantes que formarían parte durante un período de transición de la Cámara baja. Estas circunscripciones contarían con reglas especiales para la inscripción y elección de candidatos. Por ejemplo, solo se podrán presentar personas que habiten o hayan sido desplazadas de estos territorios; los partidos políticos, con representación en el Congreso, no podrán inscribir candidaturas.

Para fortalecer la participación civil se pactó la construcción de veedurías y observatorios de transparencia, con especial énfasis en el control de los acuerdos firmados con el gobierno, pero también para vigilar la gestión pública. Igualmente se implementarán mayores mecanismos de intervención ciudadana en el diseño y evaluación de los planes de desarrollo locales. ${ }^{11}$

Por último, se acordó establecer medidas para garantizar y promover una cultura de reconciliación, convivencia, tolerancia y no estigmatización a los opositores políticos. Para ello se prevé el establecimiento de Consejos para la Reconciliación y la Convivencia en las comunidades.

10 El Fondo se construirá a partir de la expropiación de tierras ilegalmente adquiridas, recuperación de baldíos y la extinción administrativa de zonas inexploradas, entre otros.

11 Ver al respecto los comunicados emitidos por el equipo negociador en: http://www.indepaz.org.co/wp-content/ uploads/2013/12/segundo-informe-conjunto.pdf 
Con estas propuestas es claro que la guerrilla espera constituirse en un movimiento político y que su incorporación a la vida civil se haga en un contexto fiable. Por el momento las conversaciones siguen su curso, no sin que haya cuestionamientos sobre la validez y la legitimidad del proceso. Pese a que el gobierno en sus declaraciones enuncia la participación de organizaciones civiles, ${ }^{12}$ muchos sectores no se sienten representados en la mesa de diálogo. Otro interrogante que se cierne es la reincorporación del grupo guerrillero y la construcción de la paz en la etapa del posconflicto. El 60\% de los ciudadanos apoya el proceso, pero son renuentes a conceder beneficios políticos y judiciales a los jefes de las FARC. ${ }^{13}$ La falta de un programa claro de lo que sería el escenario posconflicto, plantea diversos problemas y debates, en torno a los castigos por crímenes cometidos durante la confrontación. Sin lugar a dudas, el mayor desafío es forjar una reconciliación que sobrepase la esfera política y reconozca el sufrimiento pasado. La reconciliación debería entrelazar las víctimas y los excombatientes con la sociedad y crear un reconocimiento del otro (Ugarriza, 2013).

\section{Colombia gana protagonismo en el ámbito internacional}

En este último año el presidente Juan Manuel Santos ha logrado consolidar los objetivos trazados desde el inicio de su gobierno: posicionar al país como un actor internacional relevante y liderar una política exterior diversificada (Ramírez, 2011). Este interés contrasta con la prioridad que tuvo en el gobierno de Álvaro Uribe la relación con Estados Unidos, relegando los intercambios con América Latina (Tickner, 2007).

Su liderazgo lo ha manifestado, en otros momentos, en el 2012, con la participación en el Consejo de Seguridad de la ONU, y en su admisión a la Organización para la Cooperación y el Desarrollo Económico (OCDE). En octubre de 2013 Colombia inició el proceso de adhesión. El trámite para convertirse en miembro pleno de la organización tarda alrededor de tres años. En este tiempo el país debe mejorar sus indicadores económicos y comprometerse a luchar contra la corrupción, a una mayor transparencia de sus instituciones y a la colaboración en materia fiscal. Además, debe trabajar en asuntos sociales como la desigualdad, la educación y la cobertura en salud. El ingreso de Colombia a esta institución ha sido bien percibida por los sectores económicos. Ya que la entrada definitiva repercutiría en políticas públicas de mayor calidad. Es así que más allá del "buen nombre" que esta membresía le genera al país, lo que debe esperarse es que el ingreso a este espacio multilateral finalice en la construcción de una política social más sólida.

Por otro lado, con el objetivo de diversificar sus articulaciones internacionales la Cancillería ha promovido diversas vías de acercamiento con África y Asia. No obstante, Colombia continúa vinculándose de una manera activa en el escenario latinoamericano.

12 El gobierno ha resaltado las contribuciones de la Oficina de Naciones Unidas en Colombia y del Centro de Pensamiento Para la Paz de la Universidad Nacional en los temas de participación política y cultivos ilícitos.

13 Ver "Farc, hacia una política sin armas", El Espectador, 6 de noviembre de 2013.

http://www.elespectador.com/noticias/paz/farc-una-politica-sin-armas-articulo-456967 
Así lo muestra su participación en la Unión de Naciones Suramericanas (Unasur) ${ }^{14}$ y la presidencia protempore de la Alianza del Pacífico. ${ }^{15}$

Adicionalmente, las relaciones con los países vecinos atraviesan por su mejor momento. Luego del incidente diplomático con Venezuela, por la visita del líder de la oposición, Henrique Capriles a Colombia, el presidente Maduro ha manifestado su apoyo incondicional al proceso de paz. Por su parte, las relaciones diplomáticas con Ecuador parecen haber superado todos los impasses suscitados en el gobierno de Uribe. El presidente Correa retiró las dos demandas entabladas contra Colombia. La primera, por las fumigaciones en la frontera. La segunda, por la muerte de un ciudadano ecuatoriano en los bombardeos contra las FARC. Pese a las excelentes perspectivas que tiene Colombia en el ámbito internacional, aún no se clarifica la posición del país frente al litigio limítrofe con Nicaragua.

\section{El conflicto con Managua}

La incertidumbre frente a la posición que asumirá Colombia ante la resolución de La Haya ${ }^{16}$ se convirtió en otro motivo de polarización en el país. Si bien el actual gobierno ${ }^{17}$ solo fue el receptor de un litigio que se emprendió desde la presidencia de Andrés Pastrana, ha sido el blanco de duras críticas. Se le objeta que durante dos años no informó a los isleños del curso de la demanda, ni preparó una respuesta contundente al fallo (Ramírez, 2013). En este escenario los expresidentes se han alineado en dos arenas opuestas: los que piden desconocer el fallo, y los que prefieren agotar los canales diplomáticos y buscar una negociación.

La posición del Ejecutivo ha sido vaga. Por un lado, el Presidente ha reiterado la inaplicabilidad del fallo, una posición que para muchos es insostenible. Pero, por otro, la canciller María Ángela Holguín ha expresado que Colombia no desconoce la sentencia, ni la jurisdicción de la Corte Internacional de Justicia y, por el contrario, está habilitando todos los canales de diálogo con el gobierno nicaragüense.

La sentencia que modificó los límites entre las dos naciones -la línea divisoria avanzó hacia el este del meridiano 82- y le otorgó a Nicaragua los derechos económicos de 75.000 kilómetros cuadrados en el mar Caribe perjudica, considerablemente, los intereses económicos del país y de los sanandresanos. En esta zona se ubica un importante banco de pesca para los raizales, tradicionalmente pescadores artesanales.

En este contexto, el Presidente, en sus alocuciones, ha reiterado que los límites de la nación no pueden ser modificados por la CIJ y que se están ejecutando todas las medidas necesarias para revertir el dictamen. La primera respuesta del gobierno fue retirarse

14 Entre mayo de 2011 a junio de 2012 Colombia tuvo la Secretaría General de Unasur.

15 Por ahora, solo México y Colombia han firmado el Acuerdo Marco de la Alianza. El Congreso chileno ya aprobó su adhesión y queda pendiente el trámite parlamentario en Perú.

16 El 12 de noviembre de 2012 la Corte Internacional de Justicia emitió el fallo de la demanda interpuesta por Nicaragua, en 2001, sobre la delimitación territorial y marítima en el Caribe Occidental. Nicaragua en 1980 declaró nulo e inválido el Tratado de Límites Esguerra-Bárcenas, firmado en 1928, cuando Nicaragua estaba ocupada por tropas estadounidenses.

17 Ver al respecto los informes de la Cancillería en: http://www.cancilleria.gov.co/casos_corte/nicaragua_colombia 
del Pacto de Bogotá, un tratado por el cual el país reconocía la jurisdicción de la CIJ. Como segunda medida, el Ejecutivo expidió un decreto que declara la existencia de una Zona Contigua Integral. Recogiendo los principios de la Convención del Mar, juntó todas las zonas insulares del Caribe occidental y redefinió la plataforma continental desde San Andrés hasta Cartagena. Para algunos analistas el decreto no tendrá efectos internacionales, a menos que Nicaragua acepte compartir estas áreas. De allí que el objetivo de fondo sea presionar al presidente Ortega para una negociación bilateral (Ramírez, 2013). En tercer lugar, ha solicitado a la UNESCO el reconocimiento de los derechos sobre la protección de la Reserva Seaflower.

Por ahora, la lentitud del gobierno para tomar una decisión frente a la sentencia de la Corte y la falta de espacios de diálogo para involucrar a la sociedad, en especial a los raizales. Por ahora, la lentitud del gobierno para tomar una decisión frente a la sentencia de la Corte y la falta de espacios de diálogo para involucrar a la sociedad, en especial a los raizales, ha creado en la opinión pública una sensación de desconcierto ha creado en la opinión pública una sensación de desconcierto.$^{18}$ En miras a las próximas elecciones, algunos líderes políticos podrían incluso aprovechar esta oportunidad para enarbolar las banderas del nacionalismo colombiano.

\section{EL MAPA POLÍTICO PARA EL 2014}

En un panorama de enfrentamientos sociales, que pone de manifiesto los problemas estructurales del país y el déficit de participación ciudadana, Colombia emprende una nueva contienda electoral. Además de definirse el rumbo que pueden tomar las conversaciones con las FARC, los resultados de los comicios también reconfigurarán el sistema político.

Desde la Constitución de 1991, las reformas electorales han buscado modificar el sistema de partidos y el comportamiento interno de estas agrupaciones. Es así que en la década de los noventa la principal apuesta institucional fue permitir la participación de terceras fuerzas, hasta ahora excluidas por el bipartidismo. Luego, en 2003, la atomización de los partidos obligó a un nuevo cambio electoral, para cohesionar los partidos y propiciar una unidad de acción. En los últimos años la filtración de grupos armados ilegales en la política y los constantes escándalos de corrupción dieron pie a una última reforma que busca fortalecer las organizaciones políticas. En las elecciones nacionales de 2014 serán aplicadas por primera vez las reglas electorales definidas en la Reforma de 2009 y en la Ley 1475 de 2011 sobre el funcionamiento de los partidos. El primer cambio constitucional aprobó un incremento del umbral (del 2\% al 3\%) en la elección del Senado. Esta disposición supone un obstáculo para ciertos partidos minoritarios, como el MIRA, que al no contar con un caudal electoral del $3 \%$ de los votos válidos podrían perder su representación en el Congreso. Así, la representación en el próximo Congreso puede

18 Ver al respecto Tickner Arlene, “Lecciones del problema limítrofe”, El Tiempo, 2 de mayo de 2012. Consultado en http://www.elespectador.com/impreso/opinion/columna-343045-lecciones-del-problema-limitrofe 
verse reducida a ciertos partidos mayoritarios como el Partido de la U, el Partido Liberal (PLC) y el Partido Conservador (PCC), que tradicionalmente han mantenido el mayor porcentaje de escaños.

El debate electoral ha tenido como epicentro las negociaciones de paz de La Habana. Aunque con algunas disidencias internas, los partidos de la coalición de gobierno (PLC, PCC, Cambio Radical, Partido Verde y el Partido de la $\mathrm{U}^{19}$ ) y la oposición liderada por el PDA apelan a una solución negociada. Esto se refleja en el apoyo casi unánime de los principales partidos a la reelección de Santos. El único partido que ha matizado sus propuestas ha sido el Centro Democrático. Si bien esta organización, fundada en 2013 por el expresidente Álvaro Uribe, en un principio fue una clara detractora del proceso, sus propuestas han mudado hacia el lema "una paz con justicia". Por su parte, las elecciones para el nuevo Congreso han sido interpretadas como una nueva Asamblea Constituyente.

\section{Reelección del presidente Santos: La principal apuesta política}

El consenso que se formó entre los partidos de gobierno para buscar una solución pacífica al conflicto armado reforzó el apoyo a la administración de Santos. La confianza puesta en el proceso de paz y el manejo que le ha dado el Presidente derivó en un amplio respaldo a su reelección.

El partido Social de Unidad Nacional, por el cual llegó el presidente Santos al gobierno, le reiteró su apoyo irrestricto. Aunque algunas voces contrarias se unieron al movimiento creado por el expresidente Uribe, antiguo líder natural, el primer mandatario conserva la mayoría en el Congreso.

El Partido Liberal y Cambio Radical también confirmaron el apoyo a la candidatura de Santos. Las dos fuerzas políticas han expresado certidumbre frente al proceso que se viene adelantando en La Habana. Cambio Radical selló una alianza con el Partido de la U, al designar al jefe de esa colectividad, Germán Vargas Lleras, como candidato a la vicepresidencia. Vargas, un político de larga trayectoria, que ha participado en el Senado y en el 2010 compitió por la presidencia, trabajó con el gobierno como Ministro del Interior y de Vivienda. Tras su trabajo en el gabinete y la promoción del programa de vivienda gratis, ${ }^{20}$ consolidó una imagen favorable, para muchos, una figura que lo puede llevar a ser Presidente. Así, su postulación es percibida como un cálculo electoral certero, que sumará al caudal electoral de Santos los votos necesarios para ganar en primera vuelta.

Por su parte el Partido Conservador, miembro de la coalición de gobierno, escogió a Martha Lucía Ramírez, exministra de Defensa, como candidata presidencial. Una elección discutida, pues un sector del partido, liderado por los caciques electorales, impugnaron la decisión ante el Consejo Nacional Electoral y manifestaron su deseo de acompañar al

19 El partido PCC y el partido Verde se retiran de la coalición a finales del 2013.

20 Ver al respecto: http://www.semana.com/politica/articulo/politica-vivienda-vargas-lleras-echeverry-zanjandiferencias/259062-3 
primer mandatario en su segundo periodo. Ramírez, quien fue senadora por el Partido de la U, regresó al partido Conservador en 2010, año en el que se presentó a las primarias para elegir al candidato presidencial de esta organización. Sin embargo, la exministra no se perfila como una dura competidora de Santos. Su base electoral es muy reducida y centralizada en la capital. Como su fórmula vicepresidencial se presenta Camilo Gómez, ex-Comisionado de Paz del presidente Pastrana. Un conservador radical, que al igual que Ramírez no goza de un reconocimiento nacional ni compensa las debilidades de la candidata. Además, simboliza el fracaso de las conversaciones de paz en el Caguán. Los azules deberán diseñar una campaña contundente, que les permita crecer en las encuestas, acercarse a las regiones y afianzar las bases conservadores, gracias a las cuales obtuvieron la candidatura.

El Partido Centro Democrático luego de una convención nacional eligió a Oscar Iván Zuluaga como candidato presidencial. El triunfo de Zuluaga relegó la candidatura de Francisco Santos, antiguo vicepresidente (2002-2010), y bifurcó las fuerzas al interior del partido. Zuluaga, un político con menos experiencia, fue alcalde, senador por un período y Ministro de Hacienda del gobierno de Uribe, no se perfila como un candidato exitoso para los comicios de 2014. Al igual que Ramírez, no tiene un alto reconocimiento y no consigue avanzar en las encuestas. Su campaña, muy ligada con la de Uribe al Senado, no ha logrado diferenciar los perfiles y un gran número de votantes siguen desconociendo a Zuluaga como candidato. Para algunos sectores, el movimiento debería unirse al Partido Conservador, para crear un contrapeso al santismo.

Por su parte, las terceras fuerzas, que en general han tenido una exigua participación en los comicios electorales, se presentan de nuevo divididas. Luego de varios meses de negociaciones entre el Polo Democrático Alternativo (PDA), la Unión Patriótica (UP) y el Partido Verde, las líderes de las dos primeras organizaciones de izquierda descartaron la coalición, argumentando que no tenían coincidencias ideológicas.

La Alianza Verde en la convención que aprobó la fusión entre los verdes y los progresistas también decidió realizar una consulta abierta para elegir a su candidato. El 9 de marzo, el mismo día de las elecciones legislativas, los votantes decidirán entre Enrique Peñalosa, exalcalde de Bogotá, Jhon Sudarsky, senador del Partido Verde y Camilo Romero, senador por el PDA.

El PDA, desde la Convención de 2012 designó a Clara López como candidata a la presidencia. Por cuestiones de estrategia política el senador Robledo, con la tercera votación más alta del país en el Senado, no asumió la jefatura del partido. El riesgo que corren los partidos minoritarios de no alcanzar el umbral condicionó la selección de los candidatos. La apuesta del Polo es que Robledo, una figura carismática, arrastre la lista del partido.

\section{La incertidumbre de la izquierda}

El PDA, un partido que en sus orígenes había fusionado los movimientos de izquierda, se enfrenta a las elecciones de 2014 desunido. Si bien el Polo concentraba diferentes matices ideológicos, hoy se encuentra liderado, en exclusiva, por el MOIR. La expulsión 
del Partido Comunista, la salida de Petro y de la ANAPO desvertebraron su estructura. El dogmatismo que ha caracterizado a los jefes del MOIR ha impedido que la izquierda se presente como una fuerza de oposición cohesionada. La izquierda no ha canalizado el descontento ciudadano ni ha logrado conducir los votos que están en contra del gobierno y de un nuevo mandato con tintes uribistas.

\section{El epílogo de la izquierda en Bogotá}

Luego de que la izquierda ganara tres elecciones consecutivas en la capital, la destitución del alcalde Gustavo Petro parece consumar el apoyo que había ganado la oposición. El 9 de diciembre el procurador Alejandro Ordóñez anunció la destitución del alcalde y lo inhabilitó, durante 15 años, para ejercer funciones públicas.

El hecho que desencadenó la decisión del procurador fue la crisis de las basuras, a finales de 2012, que tuvo a Bogotá tres días sin recolección de desechos. El alcalde, mediante el acueducto de Bogotá, decidió implementar un esquema de aseo completamente público. Para las empresas privadas la medida estaba en contra de la libre competencia. Pese a ello, Petro, con un estilo personal beligerante, mantuvo su política. Cuando los operadores privados terminaron los contratos la alcaldía no contaba con los equipos ni el personal suficiente para recoger las basuras de la ciudad.

En el fallo la procuraduría alega que el mandatario asignó la prestación del servicio de aseo a dos entidades sin ninguna experiencia. Además, vulneró los derechos a la libre empresa y, por último, afirma que tales decisiones pusieron en riesgo el medio ambiente y la salud de los habitantes de Bogotá.

Estos hechos dejaron en evidencia la escasa capacidad de gestión del mandatario. Desde el primer año su administración se caracterizó por la falta de claridad en el modelo de ciudad y la improvisación en sus decisiones (Batlle, 2012). En este sentido, un programa de gobierno innovador como el que pretendía Petro, se truncó por la poca capacidad de ejecución de su equipo, la incapacidad de comunicar sus logros y un estilo de gobernar que no fomentaba el consenso.

En estas circunstancias la ciudad se polarizó. A tal punto, que antes de la decisión de la procuraduría, un movimiento ciudadano, liderado por un representante a la Cámara, impulsó un comité de firmas para revocar al alcalde. Por el momento, la situación de Petro es incierta. Su defensa ha interpuesto distintos recursos de apelación y algunos ciudadanos han apelado a la Corte Constitucional para que se defienda su derecho a elegir. Por otra parte, la registraduría revisa la conveniencia de llamar a una consulta popular para ratificar la elección del alcalde.

Para muchos, aunque fueron claros los errores en la implementación del esquema de basuras, la sanción interpuesta es excesiva. Mas allá de la salida de Gustavo Petro el debate que ha quedado abierto es la censura política que pueden ejercer los entes de control sobre los representantes elegidos popularmente. En todo caso, la situación por la que atraviesa el Partido Progresista es un duro revés para la izquierda, que podría tener consecuencias no solo en lo local sino a nivel nacional. 


\section{El reconocimiento político de la UP}

La Unión Patriótica, en 1985, se constituyó como partido político luego del proceso de paz entre el presidente Belisario Betancur y la guerrilla de las FARC. Como resultado de las negociaciones el gobierno se comprometió a asegurar la participación de los dirigentes guerrilleros en las actividades políticas. Si bien la UP era el vehículo para que los integrantes de las FARC transitaran a la vida civil, otros sectores sociales también hacían parte. ${ }^{21}$ El movimiento consiguió el apoyo de la oposición y logró un importante y vertiginoso éxito electoral. En 1986 obtiene la votación más alta de la izquierda, consigue cinco senadores, nueve representantes a la Cámara, 14 diputados en los departamentos y 351 concejales.

En las elecciones posteriores, los atentados sistemáticos a los líderes ${ }^{22}$ y simpatizantes de la organización hacen que la UP pierda representación en el Congreso y en las Asambleas. En el intersticio de 1985 a 1992 fueron asesinados, por motivos políticos, más de 750 miembros ${ }^{23} \mathrm{y}$ un amplio número de militantes fueron desaparecidos. En este entorno, en el 2002, los dirigentes de la organización, considerando que no tenían las garantías para ejercer sus derechos políticos, deciden no presentarse a las elecciones. Ese mismo año, por decisión del Consejo Nacional Electoral (CNE), se les niega la personería jurídica, teniendo en cuenta que la UP no superó el umbral.

En julio de 2013, después de once años de apelaciones, el Consejo de Estado les restituye la personería jurídica. En un fallo, inédito, se reconoce que la UP no participó electoralmente por carecer de garantías, por tanto no eran aplicables los requisitos establecidos en el artículo $4^{\circ}$ de la Ley 130 de 1994 para conservar la personería. ${ }^{24}$

La legitimación de esta fuerza política puede interpretarse como un paso para allanar el camino hacia la paz. El reconocimiento de la responsabilidad del Estado frente a las graves violaciones de derechos humanos proyecta en la sociedad un imperativo de justicia. También puede considerarse como un símbolo de reparación y restitución a las víctimas y una garantía de no repetición, que puede abrir nuevos espacios políticos. Es así que la UP se presenta con 93 candidatos a la Cámara de Representantes y con Aída Avella, una exconcejal que permaneció 17 años en el exilio, como candidata presidencial.

\section{El Congreso de la paz}

Al Congreso que será elegido en marzo de 2014 se le ha tildado de Constituyente. Con un acuerdo de paz a la vista los próximos legisladores discutirán reformas trascendentales

21 En 1987 Iván Márquez, congresista de las FARC, se retira de la UP.

22 Entre ellos: Jaime Pardo Leal, Bernardo Jaramillo Ossa, Manuel Cepeda Vargas.

23 Ver al respecto el Informe del Defensor del Pueblo para el Gobierno, el Congreso y el Procurador General de la Nación", de octubre de 1992, donde se dan a conocer las conclusiones del "Estudio de casos de homicidio de miembros de la Unión Patriótica y del movimiento político Esperanza Paz y Libertad".

24 Consejo de Estado, Sala de lo Contencioso Administrativo. Sección Quinta. Radicación №: 11001-03-28-0002010-00027-00. Consejera Ponente: Susana Buitrago Valencia. Sentencia del cuatro (4) de julio de dos mil trece (2013). 
para el país. Luego de que se firme la paz, los representantes deberán concretizar los compromisos señalados en La Habana en políticas públicas viables.

De allí que en las listas para el Senado figuren políticos como el expresidente Álvaro Uribe, cabeza de lista del partido Centro Democrático; y los exgobernadores Horacio Serpa, por el Partido Liberal y Navarro Wolf, por la Alianza Verde. El regreso al Congreso de estos tres políticos no es usual en el sistema político colombiano. A diferencia de lo que sucede en otros países, las carreras políticas en Colombia se caracterizan por tener un dinámica ascendente. Luego de su paso por el Senado (Navarro, en 1991 y Serpa, en 1986) el escalón siguiente es ambicionar a la Presidencia -los dos han sido candidatos presidenciales-.

Respecto de lo anterior se pueden hacer dos lecturas. La primera, la eventual transformación del Congreso en una seudoconstituyente anima a muchos políticos a tener una voz en la asamblea. La segunda, el aumento del umbral electoral ha encendido las alarmas y los partidos, para asegurar y extender sus curules, incluyeron candidatos con bases electorales robustas. La Alianza Verde, con una baja representación en el Congreso, apeló a Navarro Wolf que concentra una alta votación en Nariño y goza de un reconocimiento nacional. Por su parte, el naciente partido Centro Democrático, que no tiene entre sus filas antiguos candidatos, precisaban los votos de Álvaro Uribe para ingresar al Congreso.

\section{¿Renovación en el Congreso?}

Históricamente, las tasas de reelección en el Senado oscilan, para cada período, en 50\%. Los políticos que consiguen llegar a esta Cámara desarrollan carreras longevas, ya que para muchos es el último escalón en su carrera. Los miembros del Senado, en general, son políticos profesionales que inician su carrera en el gobierno local y luego forman parte de la Cámara de Representantes (Botero, 2010). Las listas para el Senado reflejan esta tendencia, en ellas se mezclan viejos caciques, jóvenes figuras políticas y líderes sociales.

Como se ilustra en el Cuadro 3, aproximadamente el 50\% de los senadores, especialmente los de la coalición de gobierno (PLC, PCC, Partido de la U), aspiran a reelegirse. Otro grupo de candidatos (entre el 10\% y el 14\%) provienen de la Cámara de Representantes y buscan ascender al Senado. Los aspirantes que vienen de ocupar un puesto en el gobierno nacional son los menos representativos. Por último, un gran número de aspirantes, principalmente miembros de los partidos minoritarios (Alianza Verde, MIRA), no tienen experiencia en cargos de elección popular.

Algunos partidos como el PDA apuestan a estrategias alternativas para sumar votos. Entre sus filas reclutaron algunos líderes que encauzaron las protestas campesinas y estudiantiles. Es el caso de Sergio Fernández Granados, vocero de la MANE. Alberto Castilla, presidente del Coordinador Nacional Agrario de Colombia (CNA). Walter Benavides, representante del sector agrario, que paralizó el departamento de Boyacá. Como lo han manifestado sus directivas el objetivo del partido es canalizar el inconformismo y los votos de la protesta social.

En una tendencia similar, la lista de la Alianza Verde unifica diversas fuerzas. Candidatos de la UP, de los Progresistas y del movimiento Podemos Colombia engrosan sus filas. Igual 
que otros partidos, postulan candidatos que representan a las víctimas del conflicto armado y líderes sindicales. Es el caso de Marlene Zambrano, líder de la Fundación Desplazados de Colombia (Fundescol), y Witney Chávez Sánchez, integrante del Comité Ejecutivo de la Central Unitaria de Trabajadores (CUT), el sindicato más importante del país.

Por su parte, en los partidos tradicionales (Liberal y Conservador) no se dan indicios de renovación. Como en otras elecciones, los barones políticos dominan las listas o nominan a sus familiares como herederos de sus votos. Roberto Gerlein, senador del partido Conservador que aspira a su décimo período. Efraín Cepeda, conservador y Héctor Helí Rojas, liberal, miembros del Senado desde 1991, son algunos ejemplos. También se debe reseñar que dentro de las listas se encuentran candidatos con bagajes distintos a la actividad política como la academia y las artes.

El último elemento para detallar en la conformación de las listas es la participación de las mujeres. La Ley 1475 de 2011, entre otros aspectos, definió una cuota de género del $30 \%$ para todas las circunscripciones de cinco o más escaños. Esta acción afirmativa permitirá una vinculación más amplia de la mujer en los espacios de poder. A pesar que en los estatutos de ciertas organizaciones políticas se incorporaban principios de igualdad, muy pocas mujeres formaban parte de las listas.

Para las elecciones de 2014, como se muestra en el Cuadro 3, todos los partidos cumplen con la cuota de género. Sin embargo, como sucedió en las elecciones subnacionales de 2011, un gran porcentaje de aspirantes no tienen experiencia en cargos de elección popular (Ortega y Camargo, 2012). Un máximo de tres mujeres, por cada partido, se presentan teniendo una experiencia previa en el Senado o en la Cámara de Representantes (ver Cuadro 3). Muchas de ellas acuden a los partidos por sus lazos familiares o su rol dentro de la comunidad.

Cuadro 3. Trayectorias de los candidatos al Senado elecciones 2014

\begin{tabular}{lccccccccccr}
\hline Partido & $\begin{array}{c}\text { Curules } \\
\text { en 2010 }\end{array}$ & \multicolumn{2}{c}{$\begin{array}{c}\text { Candidatos } \\
\text { 2014 }\end{array}$} & $\begin{array}{c}\text { Antiguos } \\
\text { senadores }\end{array}$ & $\begin{array}{c}\text { Antiguos } \\
\text { Rep.Cámara }\end{array}$ & $\begin{array}{c}\text { Trabajaban } \\
\text { gobierno }\end{array}$ & $\begin{array}{c}\text { Sin } \\
\text { experiencia }\end{array}$ \\
\hline & & H & M & H & M & H & M & H & M & H & M \\
PU & 28 & 69 & 31 & 14 & 1 & 14 & 1 & 2 & 0 & 39 & 29 \\
PL & 17 & 70 & 30 & 18 & 2 & 12 & 2 & 3 & 1 & 37 & 25 \\
PC & 23 & 72 & 28 & 16 & 3 & 10 & 3 & 2 & 0 & 44 & 22 \\
Cambio Radical & 8 & 70 & 30 & 8 & 1 & 6 & 1 & 0 & 0 & 56 & 28 \\
PDA & 8 & 47 & 21 & 2 & 1 & 2 & 1 & 0 & 0 & 43 & 19 \\
MIRA & 2 & 74 & 26 & 2 & 1 & 0 & 1 & 0 & 0 & 72 & 24 \\
Alianza Verde & $5 *$ & 70 & 30 & 5 & 0 & 3 & 0 & 2 & 0 & 60 & 30 \\
Centro Democrático & 0 & 69 & 31 & 2 & 0 & 2 & 0 & 6 & 3 & 59 & 28 \\
\hline
\end{tabular}

Fuente: Elaboración propia.

* Los cinco escaños pertenecen al Partido Verde. La Alianza Verde surge de la coalición entre los progresistas y los verdes en 2010. 


\section{REFLEXIONES FINALES}

Aunque persisten ciertas falencias en las estructuras del Estado, los hechos políticos y sociales del último año del gobierno de Santos pueden ser considerados, con algunos matices, como un preámbulo de un cambio en el sistema político. Las protestas sociales propiciaron nuevos espacios de participación. La sentencia que le restituyó la personería jurídica a la UP proyectó en la sociedad un imperativo de justicia y de respeto a los derechos civiles. La ley de cuotas y la democracia interna están transformando, paulatinamente, a los partidos en organizaciones más responsables e institucionalizadas. Y, en definitiva, la posibilidad que tiene Colombia de poner fin al conflicto armado debe suponer un viraje en la política. En este escenario, el rumbo que puedan tomar las negociaciones de paz es incierto, este proceso abriga varios interrogantes, entre ellos: ¿qué pasará con el tema de la paz en las elecciones?, ¿las FARC continuarán en la mesa de diálogo independientemente de los resultados electorales? y ¿la sociedad apoyará la incorporación de las FARC a la vida civil?

\section{REFERENCIAS}

Archila, Mauricio. 2012. "El movimiento estudiantil en Colombia, una mirada histórica". OSAL, XIII (31): 71-103, mayo. Buenos Aires, CLACSO.

Archila, Mauricio. 2006. "Colombia en el cambio de siglo: actores sociales, guerra y política". Nueva Sociedad (182): 76-89.

Batlle, Margarita y Gustavo Duncan. 2013. "Colombia: un panorama menos confuso". Revista de Ciencia Política 33 (1): 101-116.

Bermúdez Liévano, Andrés. 2013. “La lista del polo: pocos políticos y muchos indignados”. La silla vacía [En línea] http://lasillavacia.com/historia/la-lista-del-polo-pocos-politicos-y-muchos-indignados-46002 [consultado el 17 de enero 2014].

Botero, Felipe (2010). “Ambitious Career-Seekers: An Analysis of Career Decisions and Duration In Latin America". Ph.D. Dissertation. University of Arizona.

Calderón, Fernando. 2012. coord. La protesta social en América Latina. Programa de Naciones Unidas para el Desarrollo - PNUD. Buenos Aires: Siglo XXI editores.

CINEP. 2013. "Luchas sociales, derechos humanos y representación política del campesinado 1988-2012". CINEP-PPP.

CINEP. 2009. “La protesta social 2002-2008: En cuestión las políticas públicas de Uribe Vélez”. CINEP-PPP.

Consejo de Estado. 2013. Sala de lo Contencioso Administrativo. Sección Quinta. Radicación N ${ }^{\mathrm{o}}$ : 1100103-28-000-2010-00027-00. Consejera Ponente: Susana Buitrago Valencia.

El Espectador. 2013. "Vamos a frenar el ánimo expansionista de Nicaragua: Presidente Santos" [En línea] http:/ / www.elespectador.com/noticias/politica/vamos-frenar-el-animo-expansionista-de-nicaraguapresid-articulo-445365 [Consultado el 17 de enero 2014].

El Espectador. 2014. "Los verdes mantienen la consulta" [En línea] http://www.elespectador.com/ noticias/politica/los-verdes-mantienen-consulta-articulo-472930 [Consultado el 17 de enero 2014].

El País.com. 2013. "Gobierno colombiano formalizó el protocolo para el ingreso a la OCDE" [En línea] http://www.elpais.com.co/elpais/colombia/noticias/gobierno-colombiano-formalizo-protocolopara-ingreso-ocde [Consultado el 17 de enero 2014].

Massé Frédéric. 2013. "Bientôt la paix en Colombie ?". Les Études du CERI (199-200). Opalc: 30-35. 
Ortega, Bibiana y Gabriel Camargo. 2012. “La nueva Ley de Cuotas en Colombia. El caso de las asambleas departamentales, 2007-2011". En Política y Territorio Análisis de las elecciones subnacionales en Colombia 2011, Wills, L. Battle (ed.), 197-220. Bogotá: PNUD-IDEA.

Pécaut, Daniel. 2013. “Desdibujamiento de la oposición 'amigo-enemigo' y 'banalización' de las prácticas atroces. A propósito de los fenómenos recientes de violencia en Colombia". Análisis Político 78: 3-27.

Portafolio. 2013. "Por qué es importante el ingreso a la Ocde" [En línea] http://www.portafolio.co/ economia/ingreso-colombia-la-ocde-1 [consultado el 17 de enero 2014].

Ramírez Socorro, 2013. Las relaciones internacionales de Colombia en 2013: ¿cambio de imagen? En Razón Pública [En línea] http://www.razonpublica.com/index.php/politica-y-gobierno-temas-27/7265las-relaciones-internacionales-de-colombia-en-2013-\%C2\%BFcambio-de-imagen.html [consultado el 17 de enero 2014].

Ramírez, Socorro. 2011. "El giro de la política exterior colombiana". Nueva Sociedad 231: 79-95.

Roth, André-Noël. 2013. "Élite de poder en Bogotá eclipsa la diversidad nacional". Colombia 2013. Un periódico-Universidad Nacional de Colombia (171).

Ruiz, Martha. 2013. 16/03/2013. “De la UP a la Marcha Patriótica”. En Semana.com [En línea] http://www. semana.com/opinion/articulo/de-up-marcha-patriotica/337188-3 [Consultado el 17 de enero 2014]

Semana. 2011. "El reconocimiento jurídico para la UP sería lo más justo: Jahel Quiroga" [En línea] http:/ / www.semana.com/nacion/articulo/el-reconocimiento-juridico-para-up-seria-mas-justo-jahelquiroga/234634-3 [Consultado el 17 de enero 2014].

Semana. 2013. "Anatomía de los paros" [En línea] http:/ / www.semana.com/nacion/articulo/anatomiaparos/354439-3 [Consultado el 17 de enero 2014].

Semana. 2013. “Crisis y revolcón en el gabinete de Santos” [En línea] http:/ /www.semana.com/nacion/ articulo/crisis-revolcon-en-el-gabinete-de-santos/356792-3 [Consultado el 17 de enero 2014].

Semana. 2013. "La rebelión de la Ruanas" [En línea] http://www.semana.com/nacion/articulo/larebelion-ruanas/355181-3 [Consultado el 17 de enero 2014].

Semana. 2013. "Qué hacer con la ambición de Nicaragua" [En línea] http:/ / www.semana.com/nacion/ articulo/que-hacer-ambicion-nicaragua/354442-3 [Consultado el 17 de enero 2014].

Semana. 2014. "La fórmula para ganar la reelección en primera vuelta" [En línea] http:/ /www.semana.com/ nacion/articulo/vargas-lleras-santos-la-formula-para-ganar-la-reeleccion-en-primera-vuelta/378475-3 [Consultado el 17 de enero 2014].

Tickner, Arlene. 2007. “Intervención por invitación. Claves de la política exterior colombiana y de sus debilidades principales". Colombia Internacional 65: 90-111.

Ugarriza, Juan Esteban. 2013. "La dimensión política del postconflicto: discusiones conceptuales y avances empíricos". Colombia Internacional 7: 141-176.

Velasco, Marcela. “Cambio institucional y protesta social en Colombia 1964-2000: Análisis de series de tiempo". Colombia Internacional 63: 70-87.

Wills-Otero, Laura; Christian Iván Benito. "De Uribe a Santos: cambios y continuidades de la política colombiana en 2011". Revista de ciencia política 32 (1): 87-107.

Zinecker, Heidrun. 2013. "Aprendizaje organizacional y aprendizaje mediante la 'historia como argumento' por parte de actores violentos no estatales. El caso de las FARC-EP en Colombia". Análisis Político 78: 63-91.

Paola Montilla es Docente de la Universidad Externado de Colombia. Tiene una Maestría en Ciencia Política de la Universidad de París III-IHEAL y es Candidata a Doctor en la Universidad de Salamanca, Becaria de la Fundación Carolina. Su investigación se centra, principalmente, en el comportamiento legislativo en los regímenes presidenciales.E-mail: p.montilla@usal.es 